\title{
Some Guidelines for Reporting National Regulations on Clinical Psychology for Papers in the Section "Politics and Education" of CPE
}

\author{
Anton-Rupert Laireiter ${ }^{\mathrm{ab}}$, Winfried Rief $^{\mathrm{c}}$, Cornelia Weise $^{\mathrm{c}}$ \\ [a] Faculty of Psychology, University of Vienna, Vienna, Austria. [b] Division of Psychotherapy and Gero-Psychology, \\ Department of Psychology, University of Salzburg, Salzburg, Austria. [c] Division of Clinical Psychology and \\ Psychotherapy, Department of Psychology, Philipps-University of Marburg, Marburg, Germany.
}

Clinical Psychology in Europe, 2019, Vol. 1(3), Article e39435, https://doi.org/10.32872/cpe.v1i3.39435

Published (VoR): 2019-09-20

Corresponding Author: Anton-Rupert Laireiter, Faculty of Psychology, University of Vienna, Liebiggasse 5, 1010 Vienna, Austria. E-mail: anton-rupert.laireiter@univie.ac.at

As pointed out in the editorial paper by Laireiter and Weise $(2019)^{1}$, manuscripts submitted to this section should address the following two topics: (1) legal regulations on education, training, and practice in clinical psychology and psychological treatment in the corresponding country, (2) specific aspects related to politics and education, e.g. prerequisites for, and contents of, training in various psychological treatments, or the relationship between clinical psychology and psychological treatment in the respective country. In addition, commentaries on university studies (e.g. Master's or Doctorate level), European harmonization, or pan-European regulations (e.g. by the European Federation of Psychologists' Associations or other organizations) are also welcome.

To facilitate writing of papers but also to make presentations from different countries equivalent and comparable, the editors decided to refine the general criteria by offering more specific guidelines for reporting national regulations in clinical psychology. These guidelines are not a must, but can be seen as a reference and support for structuring papers in this section of CPE. Additionally, authors are not bound to report about all points; they may select parts of it or even focus on only a few of them.

- Legal or state regulations for psychology: Do legal regulations for psychology exist in your country? Are they for psychology in general or for clinical psychology (or any other field of psychology) in specific? Please describe.

1) https://doi.org/10.32872/cpe.v1i1.34406 
- Legal or state regulations for psychological treatment: Are there (different/ further) legal regulations for psychotherapy? What is the relation between clinical psychology and psychotherapy, e.g. are they independent from each other (i.e. two independent professions), or is one part of the other? Which one is superior? Are other professions also subject to state regulations in your country (e.g., social workers)?

- Details of legal regulations: What are the details of national regulations for (clinical) psychologists? Is there, for example, a state law or act on psychology? Does this refer to clinical psychology? What other fields of psychology are also part of this act? Please describe the main structure of the regulations in clinical psychology. Do other state laws, e.g. insurance acts, national health system acts, regulate clinical psychology and their professional activities?

- Professional status of clinical psychologists: What is the professional status of clinical psychologists in your country? Is it a "free" profession in which clinical psychologists are allowed to take up residence and work autonomously and without instruction and supervision by any other profession (e.g. psychiatrists, physicians) in the National Health System (NHS) of your country? Is its professional activity limited to specific sectors of the NHS, e.g. to inpatient medical settings, psychiatry or psychosomatics? Do patients have direct and independent access to psychological treatment, or is access to it dependent on the referral by physicians?

- Core professional activities: What are the core professional activities of clinical psychologists provided by legal regulations in your country (e.g. assessment/ diagnostics, psychological treatment/psychotherapy, emergency interventions, preventive interventions, health promotion, counseling/coaching, supervision, teaching, research)?

- Training in (clinical) psychology: What kind of university training and postgraduate training is required to provide clinical psychological diagnostics and treatment? Give an overview on the criteria (e.g. Master in (clinical) psychology, additional requirements) and elements of training (theory, supervision, practice etc.) including hours/training units. Please comment on the curricula: Are there specific regulations for certain treatment traditions or approaches or limitations to specific traditions, e.g. psychodynamic, CBT, humanistic? Are internships in outpatient and inpatient treatment centers required and to what extent? Are there specific trainings and regulations for clinical psychologists for adults versus for children and adolescents?

- Licensing/public register: Is there any kind of licensing for clinical psychologists? What are the main criteria for receiving a license (or any other kind of public approval) as a clinical psychologist? How many clinical psychologists in your country are licensed or have another kind of public approval (e.g. being listed in a public register for clinical psychologists), for example compared to psychiatrists or (other) psychotherapists? 
- Financial situation: Are clinical psychological activities (e.g. assessment, treatment, psychotherapy) part of the national health insurance system? If yes, which activities specifically, e.g. assessment, treatment, psychotherapy, any other? What are the similarities and differences between psychological and medical psychotherapists related to payment and rights? Do clinical psychologists receive a regular salary during postgraduate training/internships?

- Clinical psychological research: What are the implications of the legal or state regulations for research, especially at university departments of clinical psychology and psychological treatments? Do outpatient clinics at university departments exist? Can patients easily access those treatment centers at psychological university institutes? What kind of obstacles do exist for research in clinical psychology and psychotherapy in your country?

- Conclusion: Final and concluding evaluation of the situation of clinical psychology in your country. Necessary changes, current discussions or concerns, goals for the future, etc.

\section{EACLIPT}

Clinical Psychology in Europe (CPE) is the official journal of the European Association of Clinical Psychology and Psychological Treatment (EACLIPT).

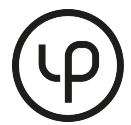

leibniz-psychology.org

PsychOpen GOLD is a publishing service by Leibniz Institute for Psychology Information (ZPID), Germany. 